\title{
El sistema de justicia administrativa chileno: revisión de la legalidad de actos administrativos o protección de derechos y/o intereses*
}

\author{
Juan Carlos Ferrada Bórquez **
}

\begin{abstract}
RESUMEN
Este trabajo realiza un análisis del sistema de justicia administrativo chileno, partir de los modelos objetivos y subjetivos formulados por la doctrina. Así, luego de un estudio de las características principales de los dos modelos de referencia, hace un análisis de las posiciones juridicas subjetivas tuteladas en los modelos subjetivos en el derecho comparado. Esto le permite hacer un estudio comparativo con el sistema chileno, el cual se construye a partir de las normas vigentes, las que permiten concluir que en nuestro derecho existe un modelo subjetivo de justicia administrativa, en la medida que la centralidad está puesta en la tutela de posiciones jurídicas subjetivas y no en los actos administrativos. Abora bien, estas posiciones jurídicas se identifican, en nuestro ordenamiento con los derechos subjetivos, aunque también se aceptan los "intereses legítimos", pero en una concepción muy limitada, lo que prácticamente los reconducen aquellos.
\end{abstract}

Justicia administrativa - contencioso subjetivo - intereses legítimos

\section{The Chilean system of administrative justice: review of the legality of the administrative acts or protection of rights and/or interests}

\begin{abstract}
This work analyses the Chilean system of judicial review based on the distinction between objective and individualised models. Having considered the main features of those models, the work focuses on the protection of individual legal positions in the context of the individualised models in a comparative perspective. This leads to look at the Chilean system, which draw on the existing rules. From here, the paper concludes that there is an individualised model of judicial review in Chilean Law since the matter is centred on the protection of individual legal positions, and not on the legality of administrative decisions. Although in Chilean law those positions amount to individual rights, it is also acceptable to include 'legitimate interests' in the concept. But the foregoing can be done only to a limited extent, such that virtually lead 'legitimate interests' back to the 'rights' category.
\end{abstract}

Administrative justice - individualised judicial review - legitimate interests

* Este trabajo forma parte del proyecto FONDECYT N 1100313 "El sistema de justicia administrativa en el derecho chileno: ¡control de legalidad al acto administrativo o tutela de derechos y/o intereses legítimos?", del que el autor es investigador principal.

** Licenciado en Ciencias Jurídicas y Sociales, Doctor en Derecho, Profesor de Derecho Administrativo de la Universidad de Valparaíso. Dirección postal: Avenida Errázuriz 2120, Valparaíso, Chile. juancarlos.ferrada@uv.cl

Artículo recibido el 30 de marzo de 2012 y aceptado para su publicación por el Comité Editorial el 31 de mayo de 2012. 


\section{INTRODUCCIÓN}

$\mathrm{L}$ a doctrina administrativa tiende a clasificar a los sistemas de justicia administrativa, más con un sentido más pedagógico que científico, en sistemas de jurisdicción contencioso administrativa objetivos o subjetivos. Esta clasificación estaría construida sobre la base de identificar el objeto primariamente controlado por los tribunales de justicia. Así, los primeros, sistemas objetivos, tendrían como característica principal la atención central sobre la legalidad de la actuación administrativa, en especial el acto administrativo formal; en cambio lo segundos, los sistemas subjetivos, mirarían a las posiciones jurídicas subjetivas objeto de protección jurisdiccional, en especial los derechos subjetivos y/o los intereses de las personas afectadas por la actividad administrativa.

Estas dos visiones de la justicia administrativa han tenido su origen, básicamente, en la contraposición clásica entre el sistema de justicia administrativo francés y alemán, en el que en el primero el contencioso administrativo desarrollado en el seno del Consejo de Estado se identificó como un control al acto - "proceso al acto” dirá la doctrina más famosa ${ }^{1}$-, especialmente a través del denominado "recurso por exceso de poder". Por el contrario, en al ámbito del derecho alemán, el sistema de justicia administrativa se centra en la tutela de derechos subjetivos, a partir de la enunciación en la Constitución de un derecho fundamental a la tutela judicial de todas las personas (artículo 19.4 de la Ley Fundamental de Bonn).

Estos modelos sirven de referencia para los otros sistemas de justicia administrativa -en particular, en el ámbito europeo continental y latinoamericano-, optando por alguno de ellos, atendido los fines principales perseguidos por el control jurisdiccional de la actividad administrativa. Así, en el caso italiano, por ejemplo, pareciera existir en un primer momento una opción por un modelo objetivo de justicia administrativa, principalmente en la configuración del sistema en el Consejo de Estado, pero ello evoluciona hacia un modelo subjetivo, radicado en los tribunales ordinarios de justicia inicialmente, para luego afectar también al propio Consejo de Estado. Algo parecido ocurre con el modelo español -desde la perspectiva del objeto controlado y no del sistema institucional de control judicial de la actividad administrativa-, aunque la evolución se produce en este caso de la mano de la Constitución de 1978.

Ahora bien, haciendo un análisis más fino, e evidente que ninguno de estos sistemas de justicia administrativa, ni otros existentes, hacen una opción cerrada por uno de los modelos teóricos antes enunciados. Al contrario, en la práctica se presenta una diversidad de modelos, atendido el objeto perseguido con el procedimiento judicial específico y los actos y derechos impugnados en cada caso. No obstante ello, los sistemas jurídicos presentan ciertas notas características que permiten acercarse a uno u otro, especialmente a partir de la configuración de la legitimación activa para acceder a la tutela judicial, en particular, a propósito de la impugnación de la legalidad del acto administrativo y la obtención de la reparación patrimonial del afectado, en su caso.

\footnotetext{
${ }^{1}$ Weil, P., Derecho Administrativo, Civitas, Madrid, 1986, p. 159.
} 
En nuestro derecho, esta opción preferente por un sistema de justicia administrativa no es clara. Aún más, las normas constitucionales y legales relacionadas con la materia no permiten fácilmente formular una respuesta, requiriendo un análisis más riguroso de los distintos datos normativos en juego. Precisamente tal análisis, especialmente desde la perspectiva de los procedimientos especiales, hace más difícil la tarea, lo que exige un trabajo sistemático de estudio y ordenación, conectando estas regulaciones especiales con las normas constitucionales en juego.

Ahora bien, en el plano doctrinal, en nuestra comunidad jurídica, la cuestión ha estado prácticamente ausente de discusión, encontrándose sólo algunas opiniones en la materia, las que, en todo caso, han sido expresadas a propósito de otras cuestiones principales analizadas por los autores. Algo parecido ocurre en nuestra jurisprudencia, aunque en ella se encuentran algunas opciones implícitas, especialmente a partir de la definición de la legitimación activa para impugnar ciertos actos administrativos.

En este contexto, este trabajo pretende formular una respuesta inicial a esta temática para el Derecho Administrativo chileno, enunciando las características principales del sistema de justicia administrativa. Para ello, en un primer apartado, revisaré los elementos principales que identifican los sistemas objetivos y subjetivos de justicia administrativa, sobre la base de lo existente en el derecho europeo continental. A continuación analizaré cómo se presentan esos mismos elementos en el derecho chileno. Finalmente enunciaré algunas conclusiones que pueden ser relevantes en esta materia.

\section{Los Sistemas SUbJetivos U OBJETIVOS DE JUSTICIA ADMINISTRATIVA}

\section{a. Los orígenes de la distinción}

La distinción entre modelos o sistemas subjetivos y objetivos de justicia administrativa es una clasificación doctrinal que se funda, como ya se adelantó, en el objeto principal del proceso, entendiendo éste como una protección de derechos y/o intereses o un proceso a la regularidad del acto ${ }^{2}$. En el primer caso, la actividad jurisdiccional se centrará en la protección de ciertas posiciones jurídicas subjetivas expuestas por las partes, las que se verían afectadas por una actuación de un órgano de la Administración del Estado. En cambio, en el segundo, la actividad del juez estará determinada por su labor de revisión de la legalidad de la actuación administrativa, independientemente que se encuentren comprometidos o no derechos y/o intereses legítimos de personas determinadas.

Esta distinción tradicional de la doctrina gala tiene sus antecedentes a fines del siglo XIX, tomando como base los procedimientos específicos utilizados por los operadores jurídicos ante el Consejo de Estado". Así, a partir de los denominados "recurso

\footnotetext{
${ }^{2}$ Gaudemet, Y., Traité de Droit Administratif, tomo 1, LGDJ, Paris, 2001, pp. 456-457.

${ }^{3}$ Ibidem, p. 456 y Chapus, R. Droit du contentieux administratif, Montchrestien, Paris, 2004, pp. 197 y ss.
} 
de plena jurisdicción” y "recurso por exceso de poder" se construirá una clasificación de los fines del proceso judicial administrativo, afectando con ello la legitimación y el contenido y alcances de la sentencia judicial que se dicte al interior del mismo.

Sin embargo, como se verá a continuación, esta distinción ha servido más modernamente para identificar los sistemas de justicia administrativa vigentes en la Europa continental $^{4}$, enmarcando a éstos en alguna de las dos opciones, aunque sin excluir totalmente la combinación de ambos en ciertos procedimientos especiales de impugnación. De este modo, aquellos sistemas jurídicos que pongan el acento principal en el control regular de los actos administrativos se adscribirán al modelo objetivo de justicia administrativa y, por el contrario, si la actividad judicial está planteada desde la perspectiva de los derechos y/o intereses afectados, el sistema será el subjetivo.

\section{b. El sistema subjetivo de justicia administrativa}

La vertiente subjetiva del contencioso administrativo consiste en que el acceso a la jurisdicción, el objeto del proceso y el contenido de la sentencia del tribunal llamado a pronunciase sobre la controversia se centran en averiguar si ha existido una lesión jurídica en los derechos de los sujetos, entendiendo por lesión jurídica el "perjuicio en los derechos del individuo ocasionado por una medida administrativa ilegal" ". En este sentido, Martín-Retortillo, siguiendo esta concepción doctrinal, señala que la justicia administrativa es, por definición, el cauce jurídico puesto a disposición del ciudadano para el restablecimiento de una lesión derivada de la inmisión de los poderes públicos en la esfera de sus derechos, teniendo siempre un carácter reparador, esquema que sigue siendo válido cuando se incluyen, además de derechos, otras situaciones jurídicas subjetivas, como son los intereses ${ }^{6}$.

Históricamente, una de las primeras manifestaciones de esta dimensión subjetiva de la justicia administrativa fue el recurso de plena jurisdicción francés, surgido a principios del siglo XIX en el seno del Consejo de Estado. Este procedimiento tenía por objeto proteger los derechos de los particulares frente a la actividad administrativa, derivado de relaciones originariamente civiles (contratos, venta de bienes públicos, relaciones de propiedad, responsabilidad civil, etc.), actuando el Consejo de Estado como un tribunal ordinario, pero en el marco de relaciones entre un órgano administrativo y un particu$\operatorname{lar}^{7}$. Así este contencioso subjetivo no tenía otro objeto que la protección jurídica del

${ }^{4}$ García de Enterría, E., "Contencioso-administrativo objetivo y contencioso-administrativo subjetivo a finales del siglo XX. Una visión histórica y comparatista”, en Revista de Administración Pública, N 152 , mayoagosto 2000, pp. 93 y ss.

${ }^{5}$ González-Varas, S., La Jurisdicción contencioso administrativa en Alemania, Civitas, Madrid, p. 89.

${ }^{6}$ Martín-Retortillo, S., "Repensando el sistema de lo contencioso-administrativo desde la perspectiva de la tutela de las situaciones jurídicas de los ciudadanos”, en Revista Aragonesa de Administración Pública, $\mathbf{N}^{\circ} 19$, diciembre 2001, p. 20.

${ }^{7}$ Gaudemet, Y., Traité de Droit Administratif, ob. cit., pp. 452-453. En el mismo sentido, García de Enterría, E., Las Transformaciones de la Justicia Administrativa: de Excepción Singular a la Plenitud Jurisdiccional. ¿Un cambio de paradigma?, Thomson/Civitas, Madrid, 2007, pp. 44-45. 
patrimonio del particular frente a la actividad administrativa, pero sin importar un control pleno de la legalidad de la actuación administrativa.

Esta perspectiva, pero en un sentido mucho más amplio y general, abarcando el control de la legalidad de la actividad administrativa, y no solo las relaciones patrimoniales, podemos también encontrarla parcialmente en el derecho alemán. Como se sabe, en el siglo XIX, en los territorios que conforman la actual Alemania, se conocieron dos modelos de jurisdicción administrativa: el del norte (Prusia), que ponía el acento en el control de la actuación administrativa de acuerdo con la legalidad (contencioso objetivo), y el del sur, centrado en los derechos individuales del sujeto (contencioso subjetivo $)^{8}$. Dichos sistemas constituían dos formas de entender la justicia administrativa, desarrollando paralelamente técnicas y mecanismos de protección de la legalidad, las cuales contribuyeron sin duda a la formación del sistema actual de control judicial de la actividad administrativa en Alemania?.

En la actualidad la doctrina mayoritaria germana ha dejado fuera de dudas que la protección de los derechos del individuo es la misión esencial de esta jurisdicción, y no un medio de control objetivo de la legalidad ${ }^{10}$. Lo anterior tendría como fundamento lo establecido en el artículo 19.4 de la Ley Fundamental de Bonn, ya que esta disposición constitucional sentaría las bases de la jurisdicción en Alemania ${ }^{11}$, tomando una opción por un sistema de tutela judicial subjetiva en el ámbito contencioso administrativo. Así, haciendo converger elementos tanto jurídico-subjetivos como institucionales del principio de Estado de Derecho, la norma citada establece un mandato explícito a los tribunales contencioso-administrativos de servir a la tutela de los derechos individuales, finalidad exclusiva del control jurisdiccional ${ }^{12}$. Lo anterior es, evidentemente, sin dejar de lado el objetivo general implícito de control de la actividad administrativa que tienen los tribunales, lo que se deriva por lo demás de la garantía integral de los derechos del particular ${ }^{13}$.

\section{c. El sistema objetivo de justicia administrativa}

Por otro lado, se encuentra el modelo objetivo de jurisdicción administrativa, el que se ha desarrollado principalmente en Francia, a partir del denominado "recurso por exceso de poder" 14 . Este procedimiento se caracteriza porque el objetivo principal que persigue es, justamente, controlar, con carácter objetivo, la legalidad de los actos ad-

\footnotetext{
${ }^{8}$ González-Varas, S., La Jurisdicción contencioso administrativa en Alemania, ob. cit., pp. 75-76.

9 Ibidem, pp. 76-77.

10 Ibidem, p. 75.

${ }^{11}$ Heyde, W., "La jurisdicción”, en Benda, Maihofer, Vogel, Hesse y Heyde, Manual de Derecho Constitucional, Marcial Pons, Madrid, 2001, pp. 787-790.

12 Schmidt-Assmann, E., La teoría general del derecho administrativo como sistema, Marcial Pons, Madrid,

${ }^{13}$ González-Varas, S., La Jurisdicción contencioso administrativa en Alemania, ob. cit., p. 77.

${ }^{14}$ Gaudemet, Y., Traité de Droit Administratif, ob. cit., p. 458.
} 2003, p. 226. 
ministrativos impugnados, declarando en la sentencia la conformidad o disconformidad del acto enjuiciado con la ley ${ }^{15} \mathrm{y}$, en consecuencia, declarando la nulidad del acto administrativo ${ }^{16}$.

Según la doctrina más autorizada ${ }^{17}$, este procedimiento surge como un mecanismo ordinario de recepción y resolución de las denuncias formuladas por los ciudadanos frente a graves irregularidades cometidas por los órganos de la Administración del Estado. Estas irregularidades afectarían a los ciudadanos, pero no serán constitutivas de un daño patrimonial directo derivado de una relación civil con el Estado, sino que importan una afectación genérica a sus derechos o intereses. De este modo, lo tutelado por la justicia administrativa, en este caso, no son derechos de los particulares, sino la legalidad misma -o el respeto al ordenamiento jurídico en su conjunto, en términos más institucionales-, no siendo exigible la presencia necesaria de aquellos para el ejercicio de la actividad judicial.

En este sentido, en el "recurso por exceso de poder" no existe propiamente un proceso entre partes, ya que no hay técnicamente -al menos, en el sentido tradicional- una demanda de derechos de un particular frente a la Administración del Estado, tutelando sus posiciones jurídicas, sino un proceso objetivo al acto, siendo la legalidad formal de la actuación administrativa la que se somete a revisión judicial ${ }^{18}$. De ahí que la sentencia judicial que recae en estos procesos, en general, no declara derechos a favor del recurrente, sino que sólo anula el acto administrativo atacado, ya que es éste el objetivo principal perseguido en la especie. Así, en el sistema francés, si el particular desea obtener un derecho o una condena de la Administración favorable a sus intereses debe optar por otro procedimiento judicial, particularmente, como ya se señaló, el denominado "recurso de plena jurisdicción”, mecanismo establecido en el ordenamiento jurídico francés para la tutela directa de derechos de los particulares ${ }^{19}$.

Sin embargo, la doctrina más moderna ${ }^{20}$ considera que esta concepción del "recurso por exceso de poder" y del sistema de justicia administrativa francés en el ámbito del contencioso administrativo anulatorio ha cambiado notablemente en los últimos 30 años. Así, por una parte, las modificaciones legislativas de 1980 y 1995, ampliaron considerablemente los efectos de la sentencia en el "recurso por exceso de poder", pudiendo obtenerse a través de ésta, ya no sólo la anulación del acto impugnado, sino también una condena a la Administración, estableciendo, por ejemplo, una obligación

${ }^{15}$ García de Enterría, E., "Contencioso-administrativo objetivo y contencioso-administrativo subjetivo a finales del siglo XX. Una visión histórica y comparatista”, ob. cit., pp. 94-95.

${ }^{16}$ Vedel, G., Derecho Administrativo, Biblioteca Jurídica Aguilar, Madrid, 1980, p. 459.

${ }^{17}$ García de Enterría, E., Las Transformaciones de la Justicia Administrativa: de Excepción Singular a la Plenitud Jurisdiccional. ¿Un cambio de paradigma?, ob. cit., p. 46.

${ }^{18}$ García de Enterría, E., Contencioso-administrativo objetivo y contencioso-administrativo subjetivo a finales del siglo XX. Una visión histórica y comparatista, ob. cit., p. 94.

${ }^{19}$ Gaudemet, Y., Traité de Droit Administratif, ob. cit., pp. 452-453.

${ }^{20}$ García de Enterría, E., Las Transformaciones de la Justicia Administrativa: de Excepción Singular a la Plenitud Jurisdiccional. ¿Un cambio de paradigma?, ob. cit., pp. 130-131. 
de hacer ${ }^{21}$. Asimismo, la reforma del año 2000 incorporó las medidas cautelares al ámbito contencioso administrativo (référés), lo que implicó la tutela directa en el proceso administrativo de los derechos de los particulares, superándose así la mera declaración de ilegalidad en el proceso $^{22}$.

Por otro lado, estas reformas legislativas y el cambio de perspectiva del contencioso anulatorio francés parecen estar fuertemente influidos por el amplio reconocimiento que ha tenido desde la postguerra en todos los ordenamientos jurídicos europeos -y por influencia, los latinoamericanos-, del derecho fundamental a la tutela judicial, particularmente a partir de lo establecido en el artículo $6^{\circ}$ de la Convención Europea de Derechos Humanos $^{23}$. Ello ha generado, aparentemente, un cambio de paradigma en la actividad judicial, lo que ha afectado también fuertemente a la justicia administrativa, ya que se empieza a mirar a aquella como un mecanismo privilegiado de protección de los derechos particulares, lo que en el ámbito contencioso administrativo ha significado reconfigurar estos procesos al mismo nivel que el proceso civil entre privados ${ }^{24}$.

\section{d. El impacto de la evolución del sistema de justicia francés en el derecho europeo}

Esta evolución de la justicia administrativa en Francia, especialmente en el ámbito del contencioso administrativo anulatorio, desde un modelo estrictamente objetivo a uno más subjetivo, ha tenido también impacto en otros ordenamientos seguidores de la tradición gala. Así, en el caso italiano, por ejemplo, que siguió en principio el modelo francés de contencioso administrativo, aunque en un sistema de doble jurisdicción (administrativa y ordinaria), con procedimientos distintos, dependiendo de si la tutela recaía sobre derechos o intereses ${ }^{25}$, se ha avanzado progresivamente desde un modelo objetivo a uno mixto, en que también se presentan características o elementos del modelo subjetivo. En este sentido, la doctrina sostiene ${ }^{26}$ que pese a que nunca ha estado unánimemente aceptado el modelo al que se adscribe el Derecho Administrativo italiano, ha existido una tendencia a un cambio de visión, del modelo objetivo puro a uno más subjetivo, particularmente en el caso de los procedimientos judiciales incoados ante el Consejo de Estado.

A todo lo anterior han influido ciertamente, además, las normas dispuestas en la Constitución italiana de 1948 (artículos 24 y 113), y la transformación que ha sufrido

${ }^{21}$ Ibídem, p. 82. Lo anterior es sin perjuicio de la existencia actualmente de contenciosos objetivos de plena jurisdicción como sería el contencioso electoral. Vid, Gaudemet, Y., Traité de Droit Administratif, ob. cit., p. 458.

${ }^{22}$ García de Enterría, E., Las Transformaciones de la Justicia Administrativa: de Excepción Singular a la Plenitud Jurisdiccional. ¿Un cambio de paradigma?, ob. cit., pp. 91 y ss.

23 Ibídem, pp. 93-94.

${ }^{24}$ Ibidem, p. 135.

25 Corso, G., La giustizia ammnistrativa, Il Mulino, Bologna, 2005, pp. 18 y ss. En el mismo sentido, Cassarino, S., "El problema de la jurisdicción administrativa", en Documentación Administrativa, $\mathrm{N}^{\circ} 248-249$, mayo-diciembre 1997, pp. 214-215.

${ }^{26}$ Cassarino, S., "El problema de la jurisdicción administrativa”, ob. cit., p. 224. 
el objeto mismo del proceso administrativo. Así, este proceso ha dejado de estar concentrado en el acto mismo, para pasar a preocuparse de la relación jurídica, reforzando la teoría de la existencia en esta materia de un verdadero "proceso entre partes", cada vez más cercano al proceso civil, pero donde siempre está presente el control de la legalidad de las actuaciones ${ }^{27}$.

Algo similar ha ocurrido en el caso español. El punto de partida también parece ser un modelo objetivo de justicia administrativa, centrado fundamentalmente en la actividad administrativa y no en la tutela de posiciones jurídicas subjetivas. De ello da buena cuenta el artículo 106 de la Constitución española de 1978 que, siguiendo en parte la doctrina tradicional dominante formulada al amparo de la Ley de la Jurisdicción Contenciosa Administrativa de 1956, señala como objetivos principales de la justicia administrativa el control de la potestad reglamentaria y la legalidad de la actuación administrativa $^{28}$. No obstante, este enfoque ha cambiado en el último tiempo, a partir de una reinterpretación de los artículos 24, 103, 106 y 117 de la Constitución española, señalando que del juego de dichas disposiciones no se admite otro modelo de proceso contencioso administrativo en el ordenamiento español que no sea aquel que garantice los postulados básicos de la plenitud del sometimiento de la actuación administrativa a la ley y al derecho (artículo 103.1) y la efectividad que se predica del derecho a la tutela judicial (artículo 24) ${ }^{29}$.

En el mismo sentido, y en palabras aún más explícitas y tajantes, García de Enterría sostendrá que al estar el contencioso administrativo incluido en el artículo 24 de la Constitución española de 1978, la justicia administrativa debe ser una justicia de tutela de derechos e intereses legítimos, una tutela de posiciones subjetivas, por lo que estima que la concepción tradicional del contencioso administrativo, el modelo francés del proceso al acto, ha concluido en España ${ }^{30}$.

\section{e. Las posiciones jurídicas subjetivas tuteladas en la justicia administrativa}

Ahora bien, definido que los sistemas de justicia administrativa tienden actualmente a la tutela de posiciones jurídicas subjetivas, más que a la revisión objetiva del acto administrativo, es preciso analizar cuáles son estas posiciones protegidas por los ordenamientos jurídicos y cuál es su contenido.

En este sentido es necesario determinar si los sistemas de justicia administrativa tienden a proteger los "derechos subjetivos" en sentido estricto o también alcanza a los denominados “intereses”, sean éstos entendidos como actuales, reales, directos, legítimos, colectivos o supraindividuales.

\footnotetext{
${ }^{27}$ Ibidem, p. 227.

${ }^{28}$ Parejo, L. et alli., Manual de Derecho Administrativo, Ariel Derecho, Barcelona, 2004, p. 807.

${ }^{29}$ Fernández, J. R., Jurisdicción administrativa revisora y tutela judicial efectiva, Civitas, Madrid, 1998, p. 320.

${ }^{30}$ García de Enterría, E., Hacia una nueva justicia administrativa, Civitas, Madrid, 1995, p. 60.
} 
En el derecho comparado, "derechos subjetivos" e "intereses" son mirados como dos posiciones jurídicas diversas y no como una mera situación procesal en relación al primero, como parece configurarlo nuestro Código de Procedimiento Civil ${ }^{31}$. Así, el derecho subjetivo hace referencia a las "facultades o prerrogativas que las normas otorgan a determinados individuos, en las condiciones establecidas por ellas, para poder exigir de otros individuos ciertos comportamientos consistentes en una acción, una actividad, una omisión, abstención o tolerancia, que constituya a la vez el contenido de deberes jurídicos de esos otros”32. En el mismo sentido, García de Enterría y Fernández señalan que el derecho subjetivo se "edifica sobre el reconocimiento por el derecho de un poder a favor de un sujeto concreto que puede hacer valer frente a otros sujetos, imponiéndoles obligaciones o deberes, en su interés propio, reconocimiento que implica la tutela judicial de dicha posición"33.

Por el contrario, el interés es una categoría más abstracta, que no establece una conexión directa con deberes u obligaciones correlativas, sino con relaciones entre sujetos y objetos o bienes existentes en el ordenamiento jurídico, pero sobre los cuales la persona no tiene una titularidad excluyente. En este sentido, como señala Couture, los intereses se conectarían con una aspiración legítima, ya sea de orden pecuniario o moral ${ }^{34}$, pero sin llegar a configurar un derecho propio. Como señala Bujosa, los intereses suponen "una relación entre un sujeto y un objeto por la que se pretende evitar algún perjuicio u obtener algún beneficio. Es una relación valorativa entre un sujeto (singular o plural) y un objeto" 35 .

De entre los conceptos de interés utilizados como posición jurídica subjetiva, el de mayor relevancia para el Derecho Administrativo es la categoría de "interés legítimo", ya que a partir de ella se ha configurado una legitimación activa específica para impugnar los actos administrativos y aun para la construcción de una justicia administrativa especializada en el caso del derecho italiano. Este concepto de "interés legítimo" es muy controvertido en el derecho comparado, pero se puede relacionar con situaciones jurídico-subjetivas relacionadas con normas que regulan la actividad administrativa para satisfacer el interés general de la sociedad ${ }^{36}$.

En este contexto, el interés legítimo se configura como una posición jurídica subjetiva distinta del derecho subjetivo, lo que guarda relación con su origen en el derecho

${ }^{31}$ El artículo 23 del Código de Procedimiento Civil señala: "Los que, sin ser partes directas en el juicio, tengan interés actual en sus resultados, podrán en cualquier estado de él intervenir como coadyuvantes, y tendrán en tal caso los mismos derechos que concede el artículo 16 a cada una de las partes representadas por un procurador común, continuando el juicio en el estado en que se encuentre. Se entenderá que hay interés actual siempre que exista comprometido un derecho y no una mera expectativa, salvo que la ley autorice especialmente la intervención fuera de estos casos. Si el interés invocado por el tercero es independiente del que corresponde en el juicio a las dos partes, se observará lo dispuesto en el artículo anterior”.

\footnotetext{
32 Monti, J., Los intereses difusos y su protección jurisdiccional, ADHOC, Buenos Aires, 2005, p. 23.

33 García de Enterría, E. y Fernández, T., Curso de Derecho Administrativo, Tomo II, Civitas, Madrid, 1997, p. 37.

${ }^{34}$ Couture, E., Vocabulario Jurídico, Depalma, Buenos Aires, 1976, p. 344.

${ }^{35}$ Bujosa, L., La protección jurisdiccional de los intereses de grupo, JM Bosch Editor, Barcelona, 1995, pp. $26-27$.

${ }^{36}$ Idem, p. 34.
} 
italiano, en el que se encuentra vinculado precisamente a la ampliación de la protección jurisdiccional contra los actos administrativos a situaciones jurídicas subjetivas no constitutivas de un derecho subjetivo ${ }^{37}$. De este modo, derechos subjetivos e intereses legítimos son dos posiciones jurídicas subjetivas equivalentes, desde la perspectiva procesal, permitiendo ambas la actuación del particular ante los tribunales de justicia, impugnando un acto administrativo irregular que le afecta.

Ahora bien, esta dicotomía de posiciones jurídicas subjetivas aparece recogida en el derecho comparado, utilizando precisamente los conceptos de "derecho subjetivo" e “interés legítimo”, como elementos claves para requerir el amparo judicial y el control de la actividad administrativa. Así, en el caso del derecho italiano, la Ley de 1865, que suprimió los tribunales administrativos regionales y entregó los asuntos administrativos a los tribunales ordinarios, sólo estableció la protección judicial de los derechos subjetivos, únicas posiciones jurídicas reconocidas y justiciables en el ordenamiento. Sin embargo, a partir de la reforma de 1889, se atribuyó las demás controversias administrativas en las que no se encontraba involucrado un derecho subjetivo al Consejo de Estado, sobre la base precisamente de los “intereses legítimos”, surgiendo así la dicotomía derechos subjetivos/intereses legítimos que ha caracterizado el sistema de justicia administrativa italiana ${ }^{38}$.

Sin embargo, es preciso aclarar que esta distinción entre derechos subjetivos e intereses legítimos, como criterio de identificación de los conflictos y distribución competencial entre los tribunales ordinarios y administrativos, no ha sido fácil. En este sentido Cassarino sostiene que "la distinción entre derechos subjetivos e intereses legítimos es de por sí ambigua y extremadamente frágil y generadora de incertidumbre y frecuentes conflictos entre las dos jurisdicciones" ${ }^{39}$. Ello ha provocado, a juicio de García de Enterría, que el propio Tribunal Europeo de Derechos Humanos, en su Sentencia 33804/1996, "Mennitto con Italia", de 3 de octubre de 2000, dé cuenta de la falta de un criterio de distinción clara entre una y otra, optando por entender a la voz interés legítimo en la categoría de derechos subjetivos protegibles, de acuerdo al artículo $6^{\circ}$ del Convenio Europeo de Derechos Humanos ${ }^{40}$.

Lo anterior ha provocado que el propio legislador italiano empiece a abandonar tal criterio conceptual para hacer el reparto competencia entre ambas jurisdicciones, optando por establecer una identificación específica de las materias atribuidas a cada tribunal ${ }^{41}$. Así, en materia de empleo público, por ejemplo, en que se discute evidentemente una

${ }^{37}$ Fernández, M., "Nuevas tendencias de la justicia administrativa en Italia: hacia algunas quiebras en la distinción entre intereses legítimos y derechos subjetivos", en Revista de Administración Pública, N 154 , eneroabril 2001, pp. 508-510.

38 Cassarino, S., "El problema de la jurisdicción administrativa", ob. cit., pp. 214-215.

${ }^{39}$ Cassarino, S., "El problema de la jurisdicción administrativa”, ob. cit., p. 219.

${ }^{40}$ García de Enterría, E., Las Transformaciones de la Justicia Administrativa: de Excepción Singular a la Plenitud Jurisdiccional. ¿Un cambio de paradigma?, ob. cit., p. 116.

${ }^{41}$ Cassese, S., Las bases del Derecho Administrativo, Ministerio para las Administraciones Públicas, Madrid, 1994, pp. 367-368. 
cuestión de derecho subjetivo, ha sido transferido al juez administrativo, idea que ha tenido respaldo en la propia doctrina, en virtud de la atribución general entregada a los tribunales ordinarios o administrativos, indistintamente, de los asuntos administrativos (artículo 113 de la Constitución italiana).

En el caso alemán, como ya se señaló, la tutela judicial aparece referida expresamente a los "derechos", ya que el artículo 19.4 de la Ley Fundamental de Bonn reconoce un derecho fundamental de acceso a la jurisdicción frente a los poderes públicos, en caso de "vulneración de derechos" ${ }^{2}$. Sin embargo, un sector de la doctrina ha señalado que dentro de la categoría de "derechos", también deberían incorporarse los “intereses legítimos", en la medida que tienen una protección ofrecida y garantizada por el ordenamiento jurídico ${ }^{43}$. Estos intereses, en la versión alemana, constituirían en realidad "reflejos de Derecho" (rechtsreflex) ${ }^{44}$, los que también deberían tener protección jurisdiccional, superando la estrecha conexión que el constituyente alemán hace con los derechos. Sin embargo, esta posición es rechazada por la mayoría de la doctrina alemana, ya que se estima que ello podría abrir la puerta a la generación de un nuevo sistema de justicia administrativa centrada en el acto y no en los derechos, dando lugar a una especie de legitimación popular ${ }^{45}$.

En este sentido, García de Enterría, aunque bajo una concepción muy discutible, a favor de esta ampliación de la legitimación procesal en el derecho alemán, estima que el artículo 19.4 de la Ley Fundamental de Bonn, al consagrar como derecho fundamental la tutela jurisdiccional de cualquier derecho, incluye en ese concepto los denominados por él "derechos reaccionales", idea que estima pueden ser equiparables con los intereses legítimos del contencioso francés ${ }^{46}$. Lo anterior, puesto que, en opinión del autor, el concepto de derecho subjetivo debe ser replanteado, pues en el actual Estado de Derecho todas las ventajas o beneficios que puedan derivar del ordenamiento pasan a ser verdaderos derechos subjetivos ${ }^{47}$.

En el caso español, la doctrina señala que la justicia administrativa ampara derechos subjetivos e intereses legítimos sin distinción ${ }^{48}$, afirmación que se fundamenta en la tutela judicial amplia y genérica que se realiza de ambas posiciones jurídicas subjetivas en la Constitución española de 1978 (artículo 24.1). En este sentido, esta Constitución impuso una gran novedad al calificar todo el sistema jurisdiccional como un sistema llamado a otorgar "la tutela efectiva de los jueces y tribunales en el ejercicio de los

${ }^{42}$ Heyde, W., “La jurisdicción”, ob. cit., pp. 787-788.

43 Blanke, H-J., "La legitimación procesal -ilustrado en el derecho alemán y comparado del medio ambiente-", en Ley de la Justicia Administrativa Alemana, Abeledo Perrot/Konrad Adenauer Stiftung, Buenos Aires, 2009, p. 29.

${ }^{44}$ González-Varas, S., La Jurisdicción contencioso administrativa en Alemania, ob. cit., p. 106.

45 Blanke, H-J., "La legitimación procesal -ilustrado en el derecho alemán y comparado del medio ambiente-", ob. cit., p. 29.

${ }^{46}$ García de Enterría, E., Las Transformaciones de la Justicia Administrativa: de Excepción Singular a la Plenitud Jurisdiccional. ¿Un cambio de paradigma?, ob. cit., p. 74.

47 Ibídem, p. 137.

${ }^{48}$ González, J., Manual de Derecho Procesal Administrativo, Civitas, Madrid, 2001, p. 177. 
derechos e intereses legítimos", con lo que se estima que el sistema jurisdiccional entero se ha subjetivado ${ }^{49}$. Esto se ve confirmado, en el ámbito administrativo, con la Ley de 1998, que señala, en su artículo $1^{\circ}$, que el objeto del proceso es siempre enjuiciar las pretensiones que deduzcan los recurrentes, quienes deben invocar siempre un derecho o interés legítimo ${ }^{50}$.

Ahora bien, la jurisprudencia del Tribunal Constitucional como del Tribunal Supremo español ha realizado una interpretación extensiva del concepto de "interés legítimo", por considerarlo exigencia del derecho fundamental a la tutela judicial efectiva ${ }^{51}$. Así, la jurisprudencia ha entendido por interés legítimo "todo interés moral o material que pueda resultar beneficiado por la estimación de la pretensión" ${ }^{52}$. No obstante, este interés no es un interés abstracto por la legalidad, sino un interés concreto de estimar que la Administración del Estado le está perjudicando, cuestión que parte de la doctrina llega a considerar como un verdadero derecho subjetivo ${ }^{53}$.

En el caso del derecho francés, aun cuando el sistema de justicia administrativa está construido predominantemente desde una perspectiva objetiva, como ya se señaló, ello no impide reconocer el "interés" como concepto relevante para la legitimación activa en la justicia administrativa ${ }^{54}$. Así, pese a que el contencioso administrativo está centrado en la impugnación del acto administrativo, es decir, como proceso al acto mismo, la doctrina y la jurisprudencia exigen una posición jurídica subjetiva específica del actor para incoar el proceso judicial, el que descansa en el concepto de “interés" en términos bastante amplios, entendido como interés patrimonial o moral, individual o colectivo $^{55}$. En todo caso, esta amplia legitimación activa para perseguir la nulidad del acto administrativo en el derecho francés parece ser la consecuencia precisamente de la centralidad del control al acto en el sistema de justicia administrativa, sin que tal circunstancia condicione la actividad de los tribunales administrativos en esta tarea.

En suma, en esta rápida mirada al derecho comparado de referencia se puede apreciar que los sistemas de justicia administrativa -especialmente los que adcriben al modelo subjetivo- han optado por configurar su actividad sobre la base de los "derechos subjetivos" e "intereses legítimos", entendiendo ambas posiciones jurídicas como habilitantes para la puesta en marcha de la jurisdicción administrativa, interpretando la segunda de éstas de una forma bastante amplia, lo que permite el pleno control de la actividad administrativa. Ello incluso alcanza a los modelos más objetivos de justicia administrativa

${ }^{49}$ García de Enterría, E., "Contencioso-administrativo objetivo y contencioso-administrativo subjetivo a finales del siglo XX. Una visión histórica y comparatista”, ob. cit., p. 101.

${ }^{50}$ Ibídem, p. 102.

51 Tardío, J., "Legitimación procesal e intereses legítimos”, en Revista Española de Derecho Administrativo, $\mathrm{N}^{\circ}$ 93, enero-marzo 1997 , pp. 99 y ss.

52 González, J., Manual de Derecho Procesal Administrativo, ob. cit., p. 178.

53 García de Enterría, E. y Fernández, T., Curso de Derecho Administrativo, Tomo II, ob. cit., p. 55.

${ }^{54}$ En este sentido, ver Vedel, G., Derecho Administrativo, ob. cit., pp. 473-475

55 Chapus, R., Droit du contentieux administratif, ob. cit., pp. 447-449. 
(derecho francés), en que si bien, como ya se señaló, el sistema está construido desde la perspectiva del acto impugnado, la legitimación activa descansa sobre el concepto de “interés", entendido éste en términos bastante laxos. No obstante, en el derecho alemán, esa concepción es más limitada, ya que la mayoría de la doctrina sigue configurando la justicia administrativa sobre la base del concepto de "lesión de derechos", sin aceptar claramente otras posiciones jurídicas dignas de protección jurisdiccional.

\section{EL SISTEMA DE JUSTICIA ADMINISTRATIVA CHILENO}

\section{a. Las caracteristicas generales del sistema chileno de justicia administrativa}

En nuestro derecho, como ya se ha señalado, este tema ha sido escasamente tratado por la doctrina. La mayoría de los autores al analizar la justicia administrativa en nuestro país han concentrado sus esfuerzos en definir con claridad la competencia de los tribunales especiales y ordinarios en materia administrativa y las facultades de los órganos administrativos en la resolución de estos asuntos ${ }^{56}$.

No obstante, en el último tiempo algunos autores han avanzado en estas materias, a propósito del estudio de la legitimación activa para incoar procesos administrativos, afirmando implícitamente la existencia de un modelo subjetivo de justicia administrativa en nuestro país, aunque sin sacar todas las consecuencias de ello. Así, Cordero (Eduardo $)^{57}$ y Bordalî ${ }^{58}$ han sostenido que la justicia administrativa en nuestro medio está destinada, al igual que la actividad de los tribunales ordinarios en general, a tutelar derechos e intereses legítimos, pero sin excluir -o así yo interpreto sus trabajos- la existencia de procesos administrativos objetivos, ya que la Constitución no modela ni define un sistema de justicia administrativo acotado.

Por su parte Cordero (Luis) ha sido más explícito, ya que ha afirmado que el objeto del contencioso administrativo ha evolucionado en nuestro ordenamiento en las últimas décadas desde un sistema objetivo, similar al francés, hacia un sistema subjetivo, cercano al alemán. Ello principalmente como consecuencia de la formulación contenida en la Constitución Política de la República de 1980 (artículo 38), la que daría preeminencia a los conceptos de "acción” y "pretensión”, más que a la noción de "acto" propiamente

\footnotetext{
${ }^{56}$ Así, por ejemplo, puede verse, entre otros, Pantoja, R., La Jurisdicción contencioso administrativa: decisiones legislativas al año 2001, Fundación Facultad de Derecho Universidad de Chile, Santiago, 2001, p. 44, y "Justicia administrativa: ¿Tribunales ordinarios, tribunales de jurisdicción general o tribunales especiales de lo contencioso administrativo?", en Ferrada, J. C. (coord.), La Justicia Administrativa, LexisNexis, Santiago de Chile, 2005, pp. 105-109; Daniel, M., "Sobre el contencioso administrativo de general aplicación”, en Revista de Derecho Público, Vol. 63, 2002, p. 191.

${ }^{57}$ Cordero, E., "La legitimación activa en el proceso contencioso-administrativo", en Ferrada, J. C. (coord.), La Justicia Administrativa, LexisNexis, Santiago de Chile, 2005, pp. 394 y ss.

${ }^{58}$ Bordalí, A., "Principios de una nueva justicia administrativa en Chile", en Ferrada, J. C. (coord.), La Justicia Administrativa, LexisNexis, Santiago de Chile, 2005, pp. 372 y ss.
} 
tal $^{59}$. Ello lleva envuelto, según el mismo autor, la exclusión del control judicial en aquellos casos en que no hay lesión de derechos o cuando el titular de los mismos no acude a los tribunales, lo que debe entenderse sin perjuicio del control jurídico que realiza la Contraloría General de la República ${ }^{60}$.

Ahora bien, estos planteamientos, sin embargo, no han llegado a analizar el impacto que tiene esta definición constitucional en los procesos administrativos generales y especiales. Si bien Cordero (Eduardo) ${ }^{61}$ realiza un riguroso análisis de las posiciones jurídicas subjetivas reconocidas en los procesos generales y especiales en nuestro derecho, el enfoque es realizado desde la perspectiva de la legitimación activa sobre derechos o intereses legítimos, pero sin poner en cuestión la definición constitucional del acceso a la jurisdicción en materia administrativa (artículo 38 de la Constitución), ni menos poner en entredicho los procesos objetivos existentes en nuestro ordenamiento y las consecuencias que de ello se generan.

Desde esta perspectiva, en mi opinión, la Constitución de 1980 hace una opción clara por un modelo subjetivo de justicia administrativa, donde el núcleo central está construido sobre la idea de la "lesión de derechos", posición jurídica subjetiva desde la que debe erigirse el sistema de impugnación de los actos administrativos. En este sentido, nuestro constituyente, quizás sin quererlo, hizo una opción similar a la establecida en el derecho alemán, configurando un modelo subjetivo que condiciona la legitimación activa para incoar un proceso administrativo. Así para el constituyente, aparentemente, la revisión judicial de los actos administrativos no se configura como un proceso al acto, sino como una tutela de derechos o posiciones jurídicas subjetivas, las que deben ser esgrimidas por el demandante como requisito para la procedencia de la demanda o recurso judicial específico.

\section{b. El sistema de justicia administrativa a partir de los procedimientos judiciales de control de la actividad administrativa}

Sin perjuicio de lo expuesto en el apartado anterior, es preciso revisar si el modelo que aparentemente contiene la Constitución aparece desarrollado en la legislación infraconstitucional. En otras palabras, se trata de establecer la compatibilidad entre la declaración constitucional y el sistema de acciones o procedimientos judiciales de impugnación previstos en el ordenamiento jurídico chileno.

En este contexto, si seguimos la clasificación más general entre procesos generales y especiales de control de la actividad administrativa ${ }^{62}$, podemos apreciar en los primeros

${ }^{59}$ Cordero, L., "Procedimientos administrativos y la jurisdicción contenciosa administrativa", en Ferrada, J. C. (coord.), La Justicia Administrativa, LexisNexis, Santiago de Chile, 2005, pp. 309-310.

${ }^{60}$ Cordero, L., "El principio del control público en el Derecho Administrativo chileno", en Pantoja, R., Derecho Administrativo chileno, Editorial Porrúa/Universidad Nacional Autónoma de México, 2007, p. 723.

${ }^{61}$ Cordero, E., "La legitimación activa en el proceso contencioso-administrativo", ob. cit., pp. 405 y ss.

${ }^{62}$ Ferrada, J. C., "Los procesos administrativos en el Derecho chileno", en Revista de Derecho, Pontificia Universidad Católica de Valparaíso, Vol. XXVI, semestre I, 2011, pp. 264 y ss. 
una cierta disparidad de modelos, atendido el objeto perseguido por cada uno de ellos. Así, en el caso del recurso de protección, aunque no es propiamente un procedimiento judicial contencioso administrativo, en la práctica opera como tal ${ }^{63}$, es evidente que su construcción está hecha desde la perspectiva subjetiva, a partir de la lesión de derechos, ya que sólo si el acto administrativo vulnera alguno de los derechos fundamentales señalados en el artículo 20 de la Constitución, es posible poner en marcha este mecanismo jurisdiccional especial. Esto, en todo caso, es bastante lógico, si se atiende a la naturaleza misma del recurso de protección, como proceso urgente de tutela de derechos fundamentales, en que la privación, perturbación o amenaza de alguno de éstos, es el presupuesto de la procedencia de aquel arbitrio judicial.

En este sentido, en el caso del recurso de protección, el sistema de justicia administrativa aparece construido como un modelo estrictamente subjetivo, en que la afectación de un derecho fundamental es un elemento esencial de la existencia del proceso. De este modo, la revisión de la juridicidad del acto administrativo, en este caso específico, es una consecuencia de la tutela del derecho fundamental, elemento central del control jurisdiccional de la actividad administrativa.

Algo completamente distinto ocurre en el caso de la nulidad de derecho público, proceso de control de la actividad administrativa centrado sobre el acto mismo y no sobre los derechos. En efecto, la nulidad de derecho público, según la doctrina más tradicional $^{64}$, es un proceso judicial anulatorio que persigue dejar sin efecto un acto administrativo dictado en contravención al ordenamiento jurídico, obteniendo adicionalmente una reparación o indemnización, en el caso de que se hayan generado daños con la actividad administrativa.

Es evidente que el proceso de nulidad de derecho público está centrado en el acto mismo, al igual que el denominado "recurso por exceso de poder" francés, siendo irrelevantes, en principio, los derechos o intereses individuales afectados. La nulidad judicial del acto que se persigue tiene como fundamento la infracción a las normas jurídicas, sobre la base de alguna de las causales establecidas en la Constitución y algunas otras reconocidas (creadas) por la jurisprudencia de la Corte Suprema ${ }^{65}$, no protegiéndose directamente derecho o interés jurídico alguno.

La concepción anterior ha llevado a algunos autores a sostener una legitimación amplia en esta materia, proclamando una suerte de acción popular por la legalidad en esta materia (legitimación activa objetiva) ${ }^{66}$, lo que claramente parece exceder el ámbito

${ }^{63}$ Ferrada, J. C., "El recurso de protección como mecanismo de control contencioso administrativo", en Ferrada, J. C. (coord.), La Justicia Administrativa, LexisNexis, Santiago de Chile, 2005, pp. 129-164.

${ }^{64}$ Soto, E., "La nulidad de derecho público en el derecho chileno", en Revista de Derecho Público, № 47-48, 1990 , pp. 19 y ss.

${ }^{65}$ Ferrada, J. C., "Los procesos administrativos en el Derecho chileno”, ob. cit., p. 271.

${ }^{66}$ Fiamma, G., "Acción constitucional de nulidad y legitimación activa objetiva”, en Revista de Derecho Público, No 49, 1991, p. 95. 
de acción de este proceso ${ }^{67}$. En efecto, al igual que en el derecho francés, la doctrina y la jurisprudencia han exigido la invocación de una posición jurídica subjetiva específica para incoar el proceso de nulidad de derecho público, centrándose para ello sobre los conceptos de "derecho subjetivo" o "interés legítimo". Sin embargo, al contrario del derecho galo, la Corte Suprema ha hecho una interpretación muy restrictiva del concepto de "interés legítimo", vinculándolo estrechamente a la existencia de un "derecho subjetivo", entendiendo el primero en un sentido estrictamente patrimonial, actual y directo ${ }^{68}$.

El fundamento de esta jurisprudencia de nuestro más alto tribunal pareciera estar en la concepción que tienen algunos de sus jueces del proceso de nulidad de derecho público, atendido el tipo de controversias que se discuten y las peticiones que se someten a su consideración. Así, sobre la base de la clasificación francesa de las acciones que impugnan los actos administrativos, el proceso de nulidad de derecho público, por las peticiones concretas sometidas a decisión del tribunal, se ajustaría más a las denominadas acciones o recursos de plena jurisdicción, que el recurso por exceso de poder ${ }^{69}$. Así, la práctica habitual de los operadores jurídicos de incoar un procedimiento de nulidad de derecho público, como antecedente y fundamento de una acción reparatoria o indemnizatoria en el mismo juicio, llevaría a entender este proceso no como un proceso anulatorio propiamente tal, sino de protección de derechos subjetivos, lo que exigiría la existencia de estos últimos para estar legitimado activamente en un caso determinado.

Sin perjuicio de no estar de acuerdo con esta argumentación -de lo que no me haré cargo porque excede los límites de este trabajo-, es evidente que la consecuencia es una restricción de la operatividad del proceso de nulidad de derecho público, conectando el ejercicio de la justicia administrativa con la existencia de posiciones jurídicas subjetivas en juego. Así, por razones y fundamentos distintos, la Corte Suprema, y un sector de la doctrina, ha recuperado el concepto constitucional de "lesión de derechos" como eje del sistema de justicia administrativa, subjetivizando éste.

Ahora bien, en el caso de los procesos especiales de control de la actividad administrativa, se puede constatar una tendencia a construirse éstos sobre la base de las posiciones jurídicas subjetivas, sean éstas derechos subjetivos o intereses. Así, si se analiza la gran variedad de procedimientos especiales de reclamo o reclamación -más de un centenar

${ }^{67}$ Vid, Jara, J., La nulidad de Derecho Público ante la doctrina y la jurisprudencia, Editorial Libromar, Santiago, 2004, pp. 219-220. A mayor abundamiento, Rodolfo Aldea critica lo dicho por alguna jurisprudencia, en el sentido de atribuir a la nulidad de derecho público el carácter de acción popular, siendo que, sólo excepcionalmente, y en virtud de texto expreso, es posible interponer acciones populares, sin invocar un interés actual comprometido". Vid., Aldea, R., "Interés actual y declaración judicial en las nulidades de Derecho Público", en Revista de Derecho, Consejo de Defensa del Estado, $\mathrm{N}^{\circ} 10$, diciembre 2003, pp. 27-28.

${ }^{68}$ Ferrada, J. C., "Nuevas restricciones a la nulidad de derecho público como proceso administrativo: una jurisprudencia interesante, pero inconsistente", en Anuario de Derecho Público, Universidad Diego Portales, 2010, pp. 189 y ss.

${ }^{69}$ En este sentido, utilizando la clasificación francesa y aplicándola a un caso determinado, ver Pierry, P., "El recurso de nulidad", pp. 27 y ss. y "Otros aspectos de lo contencioso administrativo", pp. 37 y ss., ambos en Lo contencioso administrativo, Ediciones Universitarias de Valparaíso, Valparaíso, 1976; y, del mismo autor, "Notas en torno a la competencia de los tribunales ordinarios para conocer de la actividad administrativa", en Revista de Derecho, Pontificia Universidad Católica de Valparaíso, Vol. III, 1979, pp. 161 y ss. 
según la recopilación hecha por la propia Corte Suprema-, queda en evidencia que el legislador los ha configurado como recursos impugnatorios de los afectados por los actos administrativos específicos, requiriendo una legitimación activa específica para incoar el proceso judicial.

En este sentido, el procedimiento de reclamo en materia de expropiación (Decreto Ley $\mathrm{N}^{\circ}$ 2.186), el reclamo por suspensión del servicio público de telecomunicaciones (Ley $\mathrm{N}^{\circ}$ 18.168), la impugnación de sanciones que impone el Consejo Nacional de Televisión (Ley $\mathrm{N}^{\circ}$ 18.838), el reclamo por las multas que impone la Superintendencia de Electricidad y Combustibles, el reclamo por el rechazo a la inscripción en el registro de iglesias y organizaciones religiosas (Ley $\mathrm{N}^{\circ}$ 19.638), la acción de impugnación por irregularidades en un procedimiento de licitación pública (Ley $\mathrm{N}^{\circ} 19.886$ ) o el reclamo de ilegalidad por acceso a la información pública (Ley $\mathrm{N}^{\circ} 20.285$ ), por nombrar algunos, son procedimientos judiciales de impugnación de actos administrativos centrados en la tutela de posiciones jurídicas subjetivas del actor y no procesos a actos administrativos. Ahora bien, es claro que en todos ellos se impugnan actos administrativos específicos, pero la centralidad del procedimiento está puesta en el derecho o interés afectado.

Hacen excepción a este modelo algunos reclamos de ilegalidad que admiten la revisión judicial del acto, independientemente de que existan o no derechos o intereses individuales comprometidos. Muestra de ello son los reclamos de ilegalidad municipal y regional (Leyes Orgánicas Constitucionales de Municipalidades y de Gobierno y Administración Regional, respectivamente), que junto con establecer un reclamo de ilegalidad sobre la base de la afectación o agravio, también permiten la impugnación del acto por cualquier particular, por afectación del interés general de la comuna o región, según el caso. En estos casos, es evidente que existe una opción por el establecimiento de una especie de "recurso por exceso de poder", pero al contrario de lo que ha dicho la Corte Suprema ${ }^{70}$, sin abandonar totalmente el modelo subjetivo del contencioso, al contemplar especialmente también la acción impugnatoria a los agraviados o afectados por el acto y aún la obtención de una sentencia condenatoria de responsabilidad en contra de la Administración.

Quizás el caso más especial que existe en nuestro ordenamiento y que constituye una exclusiva preocupación por la actividad administrativa, y no por la tutela de derechos o intereses individuales específicos, es el denominado "recurso de amparo económico". Este arbitrio procesal, establecido por la Ley $\mathrm{N}^{\circ} 18.971$ de 1990 centra su atención en las infracciones al artículo $19 \mathrm{~N}^{\circ} 21$ de la Constitución Política de la República, otorgando una acción popular para reclamar de estas acciones. Si bien ello altera la regla general en nuestro derecho, su fundamento pareciera estar en la vinculación ideológica que hace el legislador entre la tutela de la iniciativa privada preferente en la actividad económica y el interés público, centrando el recurso en las conductas infractoras a este derecho fundamental y no en un acto administrativo formal mismo.

\footnotetext{
${ }^{70}$ Sobre el carácter de "recurso por exceso de poder" que tiene el reclamo de ilegalidad municipal, en opinión de la Corte Suprema, ver Sentencia “Hotelera Somontur S.A. con I. Municipalidad de Chillán”, rol No 4384-2008.
} 
Como se puede observar, los procesos generales y especiales a través de los cuales se hace la justicia administrativa en nuestro derecho están construidos normalmente a partir de la protección de derechos subjetivos o intereses de los afectados por la actividad administrativa, sólo contemplando excepcionalmente procesos centrados en la revisión de actos o actuaciones de la Administración del Estado. Esto implica una opción del legislador por un modelo subjetivo de justicia administrativa, lo que es coherente, en principio, con la definición constitucional en esta materia, asumiendo aquella la protección de las posiciones jurídicas subjetivas de las personas afectadas por los órganos de la Administración del Estado.

No obstante lo anterior se presenta un problema de difícil solución en nuestro derecho. ¿Qué pasa con los procedimientos judiciales que contemplan impugnaciones de actos sin que existan lesiones de derechos o intereses? La respuesta más inmediata podría ser sostener la inconstitucionalidad de dichos procedimientos, por infracción al artículo 38 de la Constitución Política. Sin embargo, en la medida que dichos procedimientos establezcan una conexión con derechos o intereses específicos, aunque sean generales, podrían salvar la objeción, guardando la coherencia del sistema jurídico. Esto implica, evidentemente, descartar por regla general la acción popular como legitimación activa en nuestro derecho, la que sólo sería admisible de forma excepcional, lo que se justificaría en la protección de derechos o intereses relevantes para el ordenamiento jurídico, que afectan a un número indeterminado de personas.

\section{c. La tutela de derechos o intereses en el sistema de justicia administrativa chileno}

Una última cuestión que es necesario analizar, en el contexto de un sistema subjetivo de justicia administrativa, es determinar qué posiciones jurídicas subjetivas específicas reconoce el ordenamiento jurídico chileno, que permitan su protección jurisdiccional y la legitimación activa suficiente para incoar un proceso judicial de control de un acto de la Administración del Estado.

En este sentido, nuevamente el punto de partida en nuestro derecho debiera ser el artículo 38 de la Constitución Política de 1980, que señala a los "derechos" como el elemento central que configura la justicia administrativa. Así, la habilitación a "cualquier persona” para recurrir a los tribunales que determine la ley, en la medida que sean "lesionados sus derechos”, define el ámbito de actuación de los tribunales en el ámbito contencioso administrativo, excluyendo en principio un contencioso objetivo en el derecho chileno.

Sin embargo, esta disposición plantea un problema inicial: a diferencia de las constituciones italiana y española, como ya se señaló, la única posición jurídica subjetiva que reconoce nuestra Constitución es el "derecho subjetivo", coincidiendo en ello con la Ley Fundamental de Bonn (artículo 19.4) ${ }^{71}$. Esto debería llevar, en principio, a reconocer sólo a los titulares de derechos subjetivos la legitimación activa para iniciar

${ }^{71}$ Cordero, L., "Procedimientos administrativos y la jurisdicción contenciosa administrativa", ob. cit., pp. 329-331. 
un proceso administrativo, excluyendo los intereses, tal como lo ha hecho la doctrina alemana mayoritaria. En este sentido, el sistema subjetivo de justicia administrativa modelado en la Constitución estaría restringido a la protección de derechos subjetivos de las personas, descartando otro tipo de posiciones jurídicas como habilitantes para acceder a la tutela judicial.

No obstante lo anterior, la doctrina procesal chilena ha sostenido, sin mucha explicación y siguiendo probablemente a la doctrina italiana y española, que el derecho de acción o a la tutela judicial en términos amplios (artículo $19 \mathrm{~N}^{\circ} 3$ de la Constitución Política de la República) se extiende en nuestro derecho a la protección de derechos subjetivos e intereses legítimos ${ }^{72}$. Ello implicaría, en el ámbito de la justicia administrativa, según esta misma doctrina, que ambas posiciones jurídicas deben ser consideradas como legitimantes en nuestro sistema ${ }^{73}$, lo que se comprobaría si se analiza la regulación específica de los contenciosos administrativos especiales, no obstante la distinta terminología utilizada en ella ${ }^{74}$.

En efecto, si analizamos estas regulaciones podemos observar que el legislador chileno utiliza frecuentemente terminología que se relaciona con la titularidad de "intereses", como posición jurídica subjetiva para incoar un proceso administrativo, haciendo alusión sólo excepcionalmente a la titularidad de derechos subjetivos. Así, si analizamos los legitimados activos en los procedimientos judiciales especiales de impugnación de los actos administrativos, veremos que la referencia es al "que tenga interés en ello" (Ley $\mathrm{N}^{\circ}$ 18.168), el que tenga "un interés actualmente comprometido" (Ley $\mathrm{N}^{\circ} 19.886$ ), "los interesados" (Ley $\mathrm{N}^{\circ}$ 19.638), los “afectados" (Ley $\mathrm{N}^{\circ}$ 18.410) o los “agraviados” (Ley $\mathrm{N}^{\circ} 19.175$ ), por nombrar sólo algunos ejemplos, lo que constituye un reconocimiento expreso al "interés" como posición jurídica subjetiva principal sobre la que están construidos los procedimientos judiciales en materia administrativa. Algo parecido ocurre con la nulidad de derecho público, la que si bien no está construida como un proceso de tutela de derechos, si exige, como ya se señaló, un interés legítimo para la legitimación activa necesaria para incoar el procedimiento judicial.

En este sentido, es evidente que la regulación de los procesos administrativos en nuestro derecho ha excedido el marco general establecido en la Constitución, habilitando el recurso a los tribunales a todas las personas, no sólo cuando se les ha lesionado un derecho subjetivo, sino además en aquellos casos en que se les ha afectado, lesionado o amagado un interés. Ello podría dar lugar a una grave controversia en nuestro derecho, ya que, aparentemente, el legislador habría ido mucho más allá de la Constitución en el establecimiento de los legitimados activos en cada procedimiento judicial, la que, siguiendo comparativamente la doctrina alemana dominante a partir de un texto similar, sólo se extendería a la titularidad de derechos subjetivos. Así, por la vía legal se habría

${ }^{72}$ Vid, Bordalí, A., "Derecho fundamental de acción: Un intento de configuración en el orden constitucional chileno", en Revista de Derecho y Jurisprudencia, Tomo XCVII, N 3, 2000, p. 90, y Romero, A., Curso de Derecho Procesal Civil, Tomo I, Editorial Jurídica de Chile, Santiago, 2006, p. 13.

73 Bordalí, A., "Principios de una nueva justicia administrativa en Chile", ob. cit., p. 372.

${ }^{74}$ Cordero, E., "La legitimación activa en el proceso contencioso-administrativo", ob. cit., pp. 406-407. 
reconocido otra posición jurídica subjetiva no considerada en la Constitución chilena, ampliando el abanico de legitimados activos para la puesta en marcha de la jurisdicción administrativa.

Sin embargo, la conclusión anterior debe ser matizada. Por un lado, por la forma en que se ha entendido el interés en el derecho chileno. Por otra, por los alcances que podría tener el término "derecho" en el artículo 38 de la Constitución.

Respecto de lo primero -el concepto de “interés” en el derecho chileno-, debe tenerse en cuenta que en el ámbito del derecho privado, a propósito de la nulidad en materia civil, el "interés” ha sido entendido, a partir de lo dispuesto en el artículo 1683 del Código Civil, como un requisito para demandar la nulidad absoluta, identificando éste con un interés actual y patrimonial ${ }^{75}$, lo que sin embargo ha sido criticado por otro sector de la doctrina ${ }^{76}$, ampliándolo a la defensa de la moral y las buenas costumbres. Asimismo, en el ámbito de la responsabilidad extracontractual, el concepto de interés se ha utilizado para configurar de una manera amplia el concepto de daño, extendiendo éste a las lesiones de derechos subjetivos e intereses ${ }^{77}$. Aun más, la doctrina civilista más clásica ${ }^{78}$, identificaba y denominaba a este interés como "legítimo", entendiendo con ello la ventaja o beneficio lícito -es decir, conforme con la moral y las buenas costumbres- de que se prive a la víctima por el hecho doloso o culpable.

Lo anterior es en parte coincidente, como ya lo se vio, con la conceptualización que se ha hecho del "interés legítimo” en el derecho comparado, en que también se le identifica con una posición jurídica de ventaja o beneficio. Sin embargo, en el ámbito administrativo este concepto se extiende no sólo a cuestiones patrimoniales, sino de la vida en general, y especialmente, de su conexión con el correcto ejercicio del poder público ${ }^{79}$.

No obstante, si revisamos la doctrina y jurisprudencia dominante en nuestro Derecho Administrativo, podemos apreciar que el concepto de interés que se utiliza es mucho más limitado que el previsto en el derecho comparado de referencia, especialmente el derecho italiano y español, conectando éste con las características de directo, actual y personal, aunque identificados formalmente con el concepto más amplio de interés legítimo ${ }^{80}$. En este sentido, el “interés” -y el "interés legítimo”, en particular- ha sido identificado por esta doctrina y jurisprudencia con los derechos, no reconociendo al interés como una

${ }^{75}$ Varas, J. A., "El interés exigido para impetrar la nulidad absoluta en el Código Civil", en Actualidad Jurídica, $\mathrm{N}^{\circ}$ 9, enero 2004, p. 197.

76 Domínguez, R., "Nulidad absoluta, necesidad de acreditar el interés patrimonial y actual en su declaración. Momento en que ha de existir el interés”, en Revista de Derecho, Universidad de Concepción, N²01, enero-junio 2002, p. 271.

77 Barros, E., Tratado de Responsabilidad Extracontractual, Editorial Jurídica de Chile, Santiago, 2006, pp. 220-221.

${ }^{78}$ Alessandri, A., De la responsabilidad extracontractual en el Derecho Civil chileno, Editorial Jurídica de Chile, Santiago, 2005, p. 154.

${ }^{79}$ Cartei, G. y Gardini, G., "La tutela del interés legítimo en el ordenamiento italiano: nuevas perspectivas para el ciudadano”, en Revista de Administración Pública, N 167, mayo-agosto 2005, p. 424.

${ }^{80}$ Ver en este sentido, Cordero, E., "La legitimación activa en el proceso contencioso-administrativo", ob. cit., pp. 399-404. 
posición jurídica subjetiva claramente diferenciada, sino como una cualificación estrictamente procesal de la relación jurídica del tercero con el objeto principal del pleito.

Lo anterior probablemente está inspirado en la concepción que existe en el derecho procesal chileno del interés, a partir de lo dispuesto en el artículo 23 del Código de Procedimiento Civil, en que se señala que "hay interés actual siempre que exista comprometido un derecho y no una mera expectativa”. Así, el interés se encuentra inevitablemente vinculado a la existencia de un derecho subjetivo, aludiendo a una conexión procesal con éste, para efectos de su intervención en un proceso judicial ${ }^{81}$. Esta concepción queda especialmente clara en el ámbito de la nulidad de derecho público, en que la jurisprudencia de la Corte Suprema, utilizando el concepto de "interés legítimo", aparentemente como posición jurídica subjetiva, la reconduce a la titularidad de derechos subjetivos ${ }^{82}$.

Cierto es que esta concepción del "interés” utilizado en la nulidad de derecho público no puede ampliarse automáticamente a los procedimientos judiciales especiales de control de la actividad administrativa, en particular, cuando la legitimación activa está construida a partir de los conceptos de interesado, afectado o agraviado, pero la forma como conecta la jurisprudencia el interés con el derecho podría hacer presumir una interpretación restrictiva de los intereses en la legitimación activa para incoar también estos procesos especiales, sobre todo cuando se persigan declaraciones de derechos o reparaciones pecuniarias.

Ahora bien, por otro lado, no se debe descartar la posibilidad de hacer una interpretación más amplia del vocablo "derecho" que utiliza el artículo 38 de la Constitución Política. En efecto, no obstante que la alusión a esa posición jurídica subjetiva podría restringir los legitimados activos para incoar un procedimiento judicial, la vinculación de las normas administrativas y las potestades públicas con intereses generales o particulares de grupos de individuos podrían flexibilizar esta interpretación literal del precepto constitucional, dando protección también a otras posiciones jurídicas relevantes que pueden ser afectadas por la actuación administrativa y que gozan de reconocimiento en el propio ordenamiento jurídico ${ }^{83}$.

Otra interpretación podría llevar a limitar seriamente el ámbito de actuación de la justicia administrativa y la protección de los particulares, restringiendo su operatividad a controversias patrimoniales entre éstos y la Administración del Estado. Los intereses públicos de los ciudadanos son un elemento de la mayor relevancia en el Derecho Administrativo, y su protección una exigencia del Estado de Derecho.

${ }^{81}$ Aldea, R., "Interés actual y declaración judicial en las nulidades de derecho público”, ob. cit., pp. 32-34.

${ }^{82}$ Ver, entre otras, Sentencia de la Corte Suprema "Sky Service S.A. con Fisco de Chile", rol No $5553-$ 2007, y "Sociedad Visal Ltda. con Empresa Portuaria de Arica”, rol N 1428-2007.

${ }^{83}$ Esta es precisamente la interpretación que hace Bachof en el marco del derecho alemán, proponiendo una interpretación extensiva del concepto "derecho" que utiliza el artículo 19.4 de la Ley Fundamental de Bonn. Ver, Blanke, J-H., "La legitimación procesal”, ob. cit., p. 29. 


\section{CONCLUSIONES}

De todo lo expuesto, es posible formular algunas conclusiones relevantes en esta materia:

1. Los sistemas de justicia administrativa han evolucionado paulatinamente hacia modelos subjetivos, especialmente a partir del reconocimiento del derecho fundamental a la acción o la tutela judicial.

2. El sistema de justicia administrativa chileno también ha tenido esta misma evolución, lo que se ha consolidado con la entrada en vigencia de la Constitución de 1980 y el reconocimiento expreso de la "lesión de derechos" como elemento central de su configuración institucional.

3. Los procesos administrativos en nuestro derecho se han alineado en general con este modelo constitucional, considerando la tutela de posiciones jurídicas subjetivas, como fundamento y finalidad de la protección jurisdiccional. Así, a partir de diversas denominaciones, ha reconocido legitimación activa para incoar estos procesos a los interesados, agraviados o afectados, estableciendo una conexión con los intereses, como categoría conceptual básica.

4. Sin perjuicio de lo anterior, el concepto de "interés" que utiliza algún sector de la doctrina y buena parte de la jurisprudencia, acerca el interés al concepto de derecho subjetivo, o al menos lo conecta procesalmente, impidiendo su identificación como una categoría conceptual separada que identifique otra posición jurídica subjetiva sustancial.

5. La práctica judicial en nuestro país hace necesario reconceptualizar el "interés legítimo" como una posición jurídica subjetiva autónoma en la justicia administrativa, reinterpretando las normas constitucionales y legales en esta materia, y ampliando la legitimación activa en estos procesos.

\section{BIBLIOGRAFÍA}

Aldea, R., "Interés actual y declaración judicial en las nulidades de Derecho Público", en Revista de Derecho, Consejo de Defensa del Estado, $\mathrm{N}^{\circ} 10$, diciembre 2003, pp. 25-34.

Aldunate, E., "La evolución de la Justicia Administrativa”, en Ferrada, Juan Carlos (coordinador), La Justicia Administrativa, LexisNexis, Santiago de Chile, 2005, pp. 1-18.

Alessandri, A., De la responsabilidad extracontractual en el Derecho Civil chileno, Editorial Jurídica de Chile, Santiago, 2005 (reimpresión).

Barros, E., Tratado de Responsabilidad Extracontractual, Editorial Jurídica de Chile, Santiago 2006.

Blanke, H-J., "La legitimación procesal -ilustrado en el derecho alemán y comparado del medio ambiente" , en Ley de la Justicia Administrativa Alemana, Abeledo Perrot/Konrad Adenauer Stiftung, Buenos Aires, 2009, pp. 21-39.

BorDALÍ, A., "El derecho fundamental de acción: Un intento de configuración en el orden constitucional chileno", en Revista de Derecho y Jurisprudencia, Tomo XCVII, N 3, 2000, pp. 81-105.

Bordalí, A., "Principios de una nueva justicia administrativa en Chile", en Ferrada, J. C. (coord.), La Justicia Administrativa, LexisNexis, Santiago de Chile, 2005, pp. 341-381. 
Bujosa, L., La protección jurisdiccional de los intereses de grupo, JM Bosch Editor, Barcelona, 1995.

Cartei, G. F. y Gardini, G., "La tutela del interés legítimo en el ordenamiento italiano: nuevas perspectivas para el ciudadano”, en Revista de Administración Pública, $\mathrm{N}^{\circ} 167$, mayo-agosto 2005, pp. 423-439.

Cassarino, S., "El problema de la jurisdicción administrativa”, en Documentación Administrativa, $\mathrm{N}^{\circ}$ 248-249, mayo-diciembre 1997, pp. 213-229.

Cassese, S., Las bases del Derecho Administrativo, Editorial Ministerio para las Administraciones Públicas, Madrid, 1994.

Chapus, R., Droit du contentieux administratif, Montchrestien, Paris, 2004.

Cordero, E., "La legitimación activa en el proceso contencioso-administrativo”, en Ferrada, J. C. (coord.), La Justicia Administrativa, LexisNexis, Santiago de Chile, 2005, pp. 383-416.

Cordero, L., "Procedimientos administrativos y la jurisdicción contenciosa administrativa", en Ferrada, J. C. (coord.), La Justicia Administrativa, LexisNexis, Santiago de Chile, 2005, pp. 301-340.

Cordero, L., "El principio del control público en el Derecho Administrativo", en Pantoja, Rolando (coord.), Derecho Administrativo chileno, Editorial Porrúa / Universidad Nacional Autónoma de México, México, 2007, pp. 597-731.

Corso, G., La giustizia amministrativa, Il Mulino, Bologna, 2005.

Couture, E., Vocabulario Jurídico, Depalma, Buenos Aires, 1976.

DANiEl, M., "Sobre el contencioso administrativo de general aplicación”, en Revista de Derecho Público, Universidad de Chile, Vol. 63, 2002, pp. 191-198.

Domínguez, R., "Nulidad absoluta, necesidad de acreditar el interés patrimonial y actual en su declaración. Momento en que ha de existir el interés”, en Revista de Derecho, Universidad de Concepción, $\mathrm{N}^{\circ}$ 201, enero-junio 2002, pp. 269-273.

FERNÁNDEZ, J. R., Jurisdicción administrativa revisora y tutela judicial efectiva, Civitas, Madrid, 1998. Fernández, MANuel, "Nuevas tendencias de la justicia administrativa en Italia: hacia algunas quiebras en la distinción entre intereses legítimos y derechos subjetivos”, en Revista de Administración Pública, $\mathrm{N}^{\circ}$ 154, enero-abril 2001, pp. 501-540.

Ferrada, Juan Carlos, "El recurso de protección como mecanismo de control contencioso administrativo”, en Ferrada, J. C. (coord.), La justicia administrativa, LexisNexis, Santiago, 2005, pp. 129-164.

Ferrada, J. C., "Nuevas restricciones a la nulidad de derecho público como proceso administrativo: una jurisprudencia interesante, pero inconsistente”, en Anuario de Derecho Público, Universidad Diego Portales, 2010, pp. 189-205.

Ferrada, J. C., "Los procesos administrativos en el Derecho”, en Revista de Derecho, Pontificia Universidad Católica de Valparaíso, Vol. XXXVI, semestre I, 2011, pp. 251-277.

Ferrada, J. C. y Bordalí, A., Estudios de Justicia Administrativa, LexisNexis, Santiago 2008.

Fiamma, G., "Acción constitucional de nulidad y legitimación activa objetiva”, en Revista de Derecho Público, N 49, año 1991, pp. 91-98.

García de Enterría, E., Hacia una nueva justicia administrativa, Civitas, Madrid, 1995.

GARCía DE ENTERría, E., "Contencioso-administrativo objetivo y contencioso-administrativo subjetivo a finales del siglo XX. Una visión histórica y comparatista”, en Revista de Administración Pública $\mathrm{N}^{\circ}$ 152, mayo-agosto 2000, pp. 93-105.

García de EnTERría, E., Las Transformaciones de la Justicia Administrativa: de Excepción Singular a la Plenitud Jurisdiccional. ¿Un cambio de paradigma? Thomson/Civitas, Madrid, 2007.

García de Enterría, E. y Fernández, T., Curso de Derecho Administrativo, Tomo II, Civitas, Madrid, 1997.

Gaudemet, Y., Traité de Droit Administratif, Tomo 1, LGDJ, Paris, 2001. 
GonzÁlez, J., Manual de Derecho Procesal Administrativo, Civitas, Madrid, 2001.

GonZÁlez-VAras, S., La Jurisdicción contencioso administrativa en Alemania, Civitas, Madrid, 1993.

Heyde, W., "La jurisdicción”, en Benda, Maihofer, Vogel, Hesse y Heyde, Manual de Derecho Constitucional, Marcial Pons, Madrid, 2001, pp. 767-822.

Jara, J., La nulidad de Derecho Público ante la doctrina y la jurisprudencia, Editorial Libromar, Santiago de Chile, 2004.

Martín-Retortillo, S., "Repensando el sistema de lo contencioso-administrativo desde la perspectiva de la tutela de las situaciones jurídicas de los ciudadanos", en Revista Aragonesa de Administración Pública, $\mathrm{N}^{\circ}$ 19, diciembre 2001, pp. 11-29.

Montr, J., Los intereses difusos y su protección jurisdiccional, ADHOC, Buenos Aires, 2005.

Pantoja, R., La jurisdicción contencioso-administrativa. Decisiones legislativas al año 2001, Fundación Facultad de Derecho Universidad de Chile, Santiago, 2001.

Pantoja, R., "Justicia administrativa: ¿Tribunales ordinarios, tribunales de jurisdicción general o tribunales especiales de lo contencioso administrativo?”, en Ferrada, J. C. (coord.), La Justicia Administrativa, LexisNexis, Santiago de Chile, 2005, pp. 93-127.

Parejo, L. et alli. Manual de Derecho Administrativo, Ariel Derecho, Barcelona, 1994.

Pierry. P., "El recurso de nulidad", en Lo contencioso administrativo, Ediciones Universitarias de Valparaíso, Valparaíso, 1976, pp. 27-36.

Pierry, P., "Otros aspectos de lo contencioso administrativo", en Lo contencioso administrativo, Ediciones Universitarias de Valparaíso, Valparaíso, 1976, pp. 37-47.

Pierry, P., "Notas en torno a la competencia de los tribunales ordinarios para conocer de la actividad administrativa", pp. 161-174.

Romero, A., Curso de Derecho Procesal Civil, Tomo I, Editorial Jurídica de Chile, Santiago, 2006.

Schmidt-Assmann, E., La teoría general del derecho administrativo como sistema, Marcial Pons, Madrid, 2003.

Soтo, E., "La nulidad de derecho público en el derecho chileno", en Revista de Derecho Público, $\mathrm{N}^{\circ}$ 47-48, 1990, pp. 11-25.

Tardio, J. A., "Legitimación procesal e intereses legítimos", en Revista Española de Derecho Administrativo, $\mathrm{N}^{\circ} 93$, enero-marzo 1997, pp. 99 y ss. (versión CD, $\mathrm{N}^{\circ} 1-100,1974-1988$ ).

VAras, J. A., "El interés exigido para impetrar la nulidad absoluta en el Código Civil", en Actualidad Jurídica, $\mathrm{N}^{\circ}$ 9, enero 2004, pp. 197-206.

Vedel, G., Derecho Administrativo, Biblioteca Jurídica Aguilar, Madrid, 1980.

WeIL, P., Derecho Administrativo, Civitas, Madrid, 1986. 